\title{
Could Primary Tumor Resection Improve Survival in Metastatic Breast Cancer?
}

\section{Rafaela Aparecida Dias de Oliveira, Lyvia Aparecida Dias Folha, Marília Davoli Abella Goulart, Maria Clara Faustino Linhares}

University of Rio Verde, Goiás - Brazil

University Hospital of Brasília, Brasília - Brazil

University of Rio Verde, Goiás - Brazil

University of Uberaba, Minas Gerais - Brazil

\begin{abstract}
Introduction: In advanced breast cancer, local treatment is considered palliative. However, although there are some polemic opinions about the surgical treatment, some of the latest studies have emphasized that in advanced cases primary tumor resection (PTR) is related to better outcomes. This review aims to evaluate how resection of the original tumor impacts women with metastatic breast cancer, considering the most recent studies about this subject. Methods: The search was performed in MEDLINE, Scopus, PMC, Current Contents and Wiley Online Library databases; 23 articles - from 2016 to 2019 - were selected and 11 were included in this review. As inclusion criteria were considered: studies presenting outcomes about resection of the primary tumor, comparison between chemotherapy/ hormone therapy/ targeted cancer therapies and surgical intervention, studies published from 2016 to 2019 and available in English, Spanish or Portuguese. We excluded those which did not approach PTR, did not present outcomes of interest (progression-free survival comparison between PTR and systemic therapy) or only discussed systemic therapy, as well as those published before 2016. Results: It was reported in 6 studies that progression-free survival is better on those who underwent surgery. PTR was also related to longer median overall survival in women submitted to surgery, up to 16 months higher when compared to the ones who were not. Enhanced survival even pertained to surgical groups regardless of tumor size. Conclusion: Based in the analysis, PTR in metastatic breast cancer can be related to higher overall survival.
\end{abstract}

Keywords: Breast cancer; breast reconstruction; progression-free survival; metastatic breast cancer; mastectomy; primary tumor resection.

\section{Introduction}

Close to $10 \%$ of women latterly diagnosed with breast cancer manifest distant metastatic disease. Major role of local management in these cases is palliative. Currently they are given systemic therapy (ST), which includes chemotherapy, hormone therapy and targeted drugs therapies. New therapeutic approaches have been done toward improved survival rates in these patients. The resection of primary tumor is one of them and is highly debatable nowadays, as, until recently, it has been seen as palliation and not expected to have impact on survival. Although there are some polemic opinions about the surgical treatment, some of the latest researches have emphasized that once the primary tumor is resected women with advanced breast cancer have better prognosis, with reasonably low risks concerning morbidity and mortality after the procedure [1-3].

The current European Society for Medical Oncology (ESMO) guidelines and the National Comprehensive Cancer Network (NCCN) guidelines have different recommendations. The National Comprehensive Cancer Network guidelines suggest the benefit from primary tumor resection (PTR) as imprecise and it should be discussed only for patients with previous good response to systemic therapy. On the contrary, the European 
Society for Medical Oncology guidelines affirm that local surgery in patients with advanced breast cancer does not mean improved survival and recommend to analyze the option in a limited group of patients in order to enhance quality of life (QoL), always considering the patient's desires [4-5].

Retrospectives studies had shown that a specific group of patients could benefit from primary tumor resection (PTR) including younger age and those presenting oligometastatic disease. Considering possible biases that can happen in these studies, recent prospective ones have tried to investigate whether primary tumor resection can improve survival or not [1-7].

In this regard, most recent evidences have suggested that women who undergo surgery to extirpate the primary tumour have improved survival [1-3], [6-11]. Primary tumor resection in this stage has shown positive impact due to multifactorial causes as increased chemotherapeutic efficacy, preventing the tumor to produce immunosuppressive factors that provide tumor cells to avoid being eliminated by the immune system and early surgery may also inhibits the initial site of metastases as well as removes non-vascularized areas where drugs could not reach previously [3], [6-7]. This review study aimed to summarize and report the latest results regarding how resection of the original tumor impacts women with metastatic breast cancer, considering studies from the last 4 years about this subject.

\section{Methodology \\ 1. Search Strategy}

Review article using the key words: breast cancer; breast reconstruction; progression-free survival; HER 2 proto oncogene protein and mastectomy. The descriptors were consulted in Health Sciences Descriptors/Medical Subject Headings (DeCS/MeSH), available on The Virtual Health Library (VHL). We performed our search in the following databases: Medical Literature Analysis and Retrieval System Online (MEDLINE), Scopus, PubMed Central (PMC), Current Contents and Wiley Online Library. Search strategies were executed according to Preferred Reporting Items for Systematic Reviews and Meta-Analyses (PRISMA).

\section{Inclusion and Exclusion Criteria}

For this data analysis we prioritized studies that described surgical treatment in advanced breast cancer. As inclusion criteria were considered: studies presenting outcomes about resection of the primary tumor, comparison between chemotherapy/ hormone therapy/ targeted drugs therapies and surgical intervention, studies published from 2016 to 2019 and available in English, Spanish or Portuguese. Those which did not approach primary tumor resection, did not present outcomes of interest (progression-free survival comparison between primary tumor resection and systemic therapy) or only discussed systemic therapy were excluded, as well as those published before 2016. Because there are only two randomized controlled trials published so far, we considered relevant to include both of them, even though the India one was published in 2015.

\section{Study Selection}

All titles and abstracts were analyzed by the authors. After reading the abstracts, we selected 23 articles. Duplicates were excluded using EndNote x9. Were analyzed 11 studies from 2016 to 2019, including randomized controlled trials, meta-analysis and systematic reviews, as outlined below (Figure 1 and table 1). 


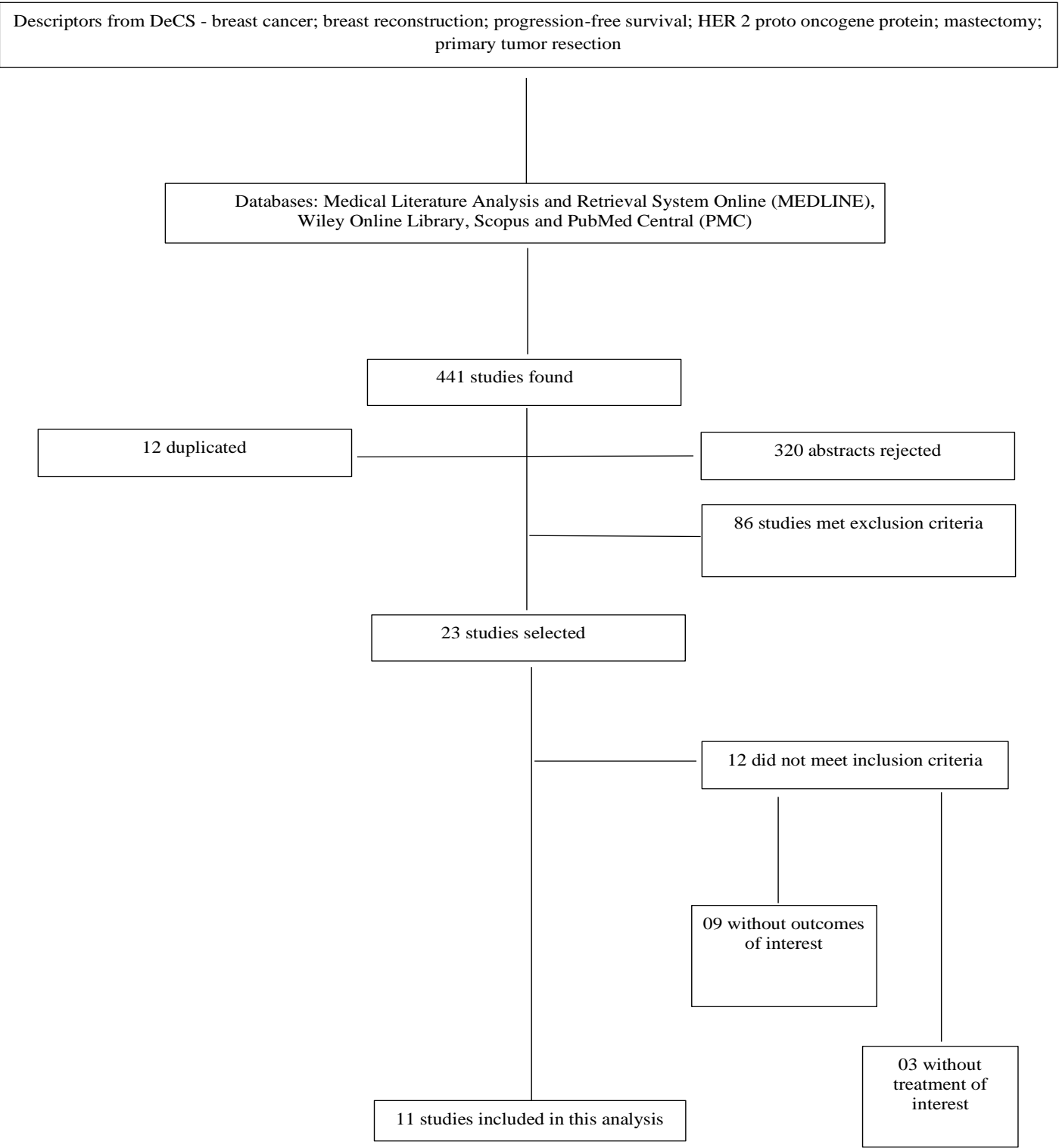

Table 1. - Included Studies

\begin{tabular}{|c|c|c|}
\hline AUTHOR & PUBLISHED IN & TYPE OF STUDY DESIGN \\
\hline Badwe et al. & 2015 & Randomized Trial \\
\hline Thomas et al. & 2016 & Retrospective cohort study \\
\hline Mendioza-Contreras et al. & 2017 & Randomized Trial \\
\hline Soran et al. & 2018 & Review Article \\
\hline Poggio et al. & 2018 & Systematic review and Meta-analysis \\
\hline Xiao et al. & 2018 & Practical consensus recommendations \\
\hline Somesekhar et al. & 2018 & Retrospective study / Propensity-matched analysis \\
\hline Vohra et al. & 2018 & Cohort study \\
\hline Lane et al. & 2019 & Retrospective cohort study \\
\hline Lopez-Tarruella et al. & 2019 & Retrospective study \\
\hline Lim et al. & 2019 & \\
\hline
\end{tabular}




\section{Quality Assessment}

To assess the quality of original papers we used the version 2 of the Cochrane risk of bias tool (RoB 2) and Appraisal Tool to Assess the Quality of Cross-Sectional Studies (AXIS), which focuses mainly on the presented methods and results. Cochrane risk of bias tool judged as low or high risk of bias or expressed "some concerns" about the study's quality [12-13].

\section{Results}

It was reported in 6 studies that progression-free survival is better on those who underwent surgery (Hazard Ratio from 0.66 to 0.361 ). Primary tumor resection also corresponded to longer median overall survival, up to 16 months higher when compared to women who did not undergo surgical resection [1-3], [6-7], [11]. The latest randomized study published, the MF07-01 trial, included 274 patients randomized in two groups: systemic therapy (ST) alone and loco-regional surgery (LRS) after ST. Median survival at median 40 months follow-up was 46 vs 37 months, in favor of loco-regional surgery group $(p=0.005)$ [6].

The other randomized controlled trial, NCT00193778, recruited untreated patients from Mumbai, India, to receive or not locoregional treatment (LRT). Median overall survival found was 20.5 vs 19.2 months, in favor of no-locoregional treatment group, which might indicate that surgical resection of the primary tumor does not lead to prolonged survival. But there are some considerations about the study: the median followup was 23 months, which is less than most trials follow through; $72 \%$ of locoregional treatment group was HER2 negative compared to $61 \%$ in the no-locoregional treatment group and in HER2 positive patients, targeted therapy was received only by no-locoregional treatment group [14].

A systematic review and meta-analysis conducted in People's Republic of China adds that, withal better progression-free survival (PFS), primary tumor resection has been reported to be related to longer PFS at a distance (Hazard Ratio $=0.42, \mathrm{p}<0.001$ ). The study pooled outcomes of 30 observational studies showed that resection of the primary tumor had significantly improved survival rates (Hazard ratio $=0.65, \mathrm{p}<$ 0.001). Improvement was also observed in those patients who had just one metastatic site, confirmed by a Hazard ratio of 0.62 . In relation to the arrangement of surgery and systematic therapy, those patients who had surgery before the systemic treatment did not present better outcomes than those who underwent only systemic therapy (Hazard ratio $=0.79, \mathrm{p}=0.16$ ), and patients that had surgery after systemic therapy showed a $44 \%$ less chance of mortality (Hazard ratio $=0.56, \mathrm{p}<0.001$ ). However, overall survival did not improve in patients with positive margin or more than 3 sites of metastasis [7]. This result is corroborated by a retrospective cohort study in the United States of America (USA) that registered survival of 10 years or more in $9.6 \%(n=353)$ of those patients who received surgery, opposed to $2.9 \%(n=107)$ of those who did not underwent surgery. Using data from the Surveillance, Epidemiology, and End Results (SEER) program, the study also demonstrated that enhanced survival even pertained to surgical groups regardless of tumor size. Additionally, women who underwent surgical resection achieved longer median survival (28 months vs 19 months) [9].

The India study, based on published evidence and practical experience, came to a consensus that the removal of primary tumor should be done in patients with oligometastatic breast cancer with previous good response to chemotherapy and in a selected subgroup of patients: young, hormone positive and responsive to systemic therapy [2]. A similar conclusion was reached by a research group in Mexico, who suggest that primary tumor resection has a positive impact on women progression-free survival and borderline overall survival, particularly benefiting those with oligometastatic disease (Hazard ratio $=0.361, p=0.035$ ). They compared 34 patients submitted to surgery to 16 who were not. All patients received systemic treatment according to their molecular profile and all operated patients received radiotherapy. Overall survival was 28.5 months versus 9.7 months in favor of surgical patients $(\mathrm{p}=0.001)$. Regarding progression-free survival, patients operated also reached higher results $(20.6$ months versus 7.5 months, $\mathrm{p}<0.0001)$. It is valuable to highlight that $91 \%$ of the patients in surgical group presented with oligometastatic disease, against only $9 \%$ of the non-surgical group [3].

Resection of the primary tumour was also related to longer median overall survival (OS) in a propensity score-matched analysis conducted in USA, which included 29916 patients classified as stage IV breast cancer, 15129 (51\%) were submitted to primary tumor resection, and 14787 (49\%) women were in the nonsurgical group. Overall survival achieved was 34 vs 18 months, in favor of surgical patients [8]. Likewise, in a retrospective study in Spain with 1.331 patients with advanced breast cancer, $44.5 \%$ were performed with 
an average follow-up of 23.3 months, the overall survival was 39.6 versus 22.4 months (Hazard ratio $=0.59$, $\mathrm{p}<0.0001$ ) in the group with young patients, with smaller tumors, higher prevalence of bone disease, oligometastatic and lower prevalence of visceral impairment [11]. Similarly, current studies show that, in women with de novo stage IV breast cancer, primary tumor resection was performed in nearly half of those alive 1 year after diagnosis [10].

In addition, a Korean study shows that, curiously, in a 5-year overall survival rate of $49 \%$ and $29.8 \%$ for surgery and no surgery, respectively, regarding tumor subtype, the luminal B had significantly better overall survival with surgery (OS rate $=63.9 \%, \mathrm{p}=0.03$ ) [15]. The reason for these results is not clear, but is hopeful considering the current prognosis for these patients and is something to be investigated in future studies.

Notwithstanding the statistical analyses, we acknowledge that there are still considerable discussions about the selection of patients, since most studies are likely to choose those with good status performance to participate in the trials. Besides, there is also possible risk of bias considering the retrospective nature of most studies and the lack of important information such as molecular classification and hormone receptors status. Also, there are significant differences on the studies relative to indications for surgery and timing of surgery.

Table 2. - Summary of Main Results

\begin{tabular}{|c|c|}
\hline STUDIE & RESULTS \\
\hline Badwe et al., 2015 & $\begin{array}{l}\text { Median overall survival of } 20.5 \text { vs } 19.2 \text { months, in favor of no- } \\
\text { locoregional treatment group. }\end{array}$ \\
\hline Thomas et al., 2016 & $\begin{array}{l}\text { Survival of at least } 10 \text { years seen in } 9.6 \%(\mathrm{n}=353) \text { and } 2.9 \% \\
(\mathrm{n}=107) \text { of those who did and did not receive surgery, } \\
\text { respectively. Improved survival was even related to surgery } \\
\text { regardless of tumor size. Additionally, patients who were submitted } \\
\text { to surgery had longer median survival than the ones who were not } \\
\text { (28 months vs } 19 \text { months). }\end{array}$ \\
\hline Mendioza-Contreras et al., 2017 & $\begin{array}{l}\text { PTR has a positive impact on women progression-free survival and } \\
\text { borderline overall survival, especially in favor of those with } \\
\text { oligomethasic disease (Hazard ratio }=0.361, \mathrm{p}=0.035) \text {. }\end{array}$ \\
\hline Lane et al., 2019 & $\begin{array}{l}\text { Surgical resection of the primary tumor can be observed at around } \\
50 \% \text { of those alive } 1 \text { year after diagnosis. }\end{array}$ \\
\hline Somsekhar et al., 2018 & $\begin{array}{l}\text { Surgery for primary tumor should be done in patients with } \\
\text { oligometastatic breast cancer. }\end{array}$ \\
\hline Vohra et al., 2018 & $\begin{array}{l}15129(51 \%) \text { underwent primary tumor resection vs. } 14787(49 \%) \\
\text { patients did not undergo surgery. OS achieved was } 34 \text { vs } \\
18 \text { months, in favor of surgical patients. }\end{array}$ \\
\hline Lim et al., 2019 & $\begin{array}{l}\text { Survival rate of } 5 \text { years was } 49 \% \text { versus } 29.8 \% \text { in favor of surgical } \\
\text { patients. Luminal B patients who underwent surgery had a } 63.9 \% \\
\text { OS versus } 33.9 \% \text { in the non-surgery group. }\end{array}$ \\
\hline Mendioza-Contreras et al., 2017 & $\begin{array}{l}\text { Primary tumor resection has been reported to be related to longer } \\
\text { progression-free survival at a distance (Hazard Ratios } 0.42 \text { ). }\end{array}$ \\
\hline $\begin{array}{l}\text { Soran et al., } 2018 \\
\text { Poggio et al., } 2018 \\
\text { Vohra et al., } 2018 \\
\text { Xiao et al., } 2018 \\
\text { Lopez-Tarruella et al., } 2019 \\
\end{array}$ & $\begin{array}{l}\text { Progression-free survival (PFS) is better on those who underwent } \\
\text { surgery. }\end{array}$ \\
\hline
\end{tabular}


Even though resection of the primary tumour is not the chosen therapy for all women in routine practice, those with metastatic disease should be assessed for local treatment if it may control local complications from the cancer, for instance, bleeding, infection and wound management. Based in the analysis, resection of the first tumor in advanced breast cancer is also related to higher survival rates when compared to not surgical groups, especially in cases which the disease is stable, that normally occur in younger women, with solitary bone metastasis and few comorbidities. We suggest new prospective studies to annul the possible selection bias discussion and the controversial results available. Hopefully, with science progress and understanding of tumor microenvironment more comprehensive groups can benefit from the surgical treatment.

Acknowledgements: None.

Conflicts of Interest: None.

Authors Contributions: All authors have equal contribution to the structure and content of this article.

\section{References}

1. F. Poggio, M. Lambertini and E. de Azambuja, "Controversies in Oncology: Surgery of the primary tumor in patients presenting with de novo metastatic breast cancer: to do or not to do?" ESMO Open, vol. 3, no. 1, pp. 1-3, 2018, doi:10.1136/esmoopen-2018-000324.

2. S. P. Somsekhar, K. Geeta, R. Jain, R. Nayyer, S. Halder, V. K. Malik, P. Parikh, S. Aggarwall and R. Koul, "Practical consensus recommendations regarding role of mastectomy in metastatic breast cancer," South Asian J Cancer, vol. 7, no. 2, pp. 79-82, 2018.

3. J. R. Mendioza-Contreras, E. Hernández-Garduño and R. Serrano-Ortíz, "Impact of primary tumor resection in patients with metastatic breast cancer," Gac. Mex. Oncol, vol. 16, no. 6, pp. 326-334, 2017.

4. F. Cardoso, E. Senkus, A. Costa, E. Papadopoulos, M. Aapro, F. André, N. Harbeck, B. Aguilar Lopez, C. H. Barrios, J. Bergh, L. Biganzoli, C. B. Boers-Doets, M. J. Cardoso, L. A. Carey, J. Cortés, G. Curigliano, V. Diéras, N. S. El Saghir, A. Eniu, L. Fallowfield, P. A. Francis, K. Gelmon, S. R. D. Johnston, B. Kaufman, S. Koppikar, I. E. Krop, M. Mayer, G. Nakigudde, B. V. Offersen, S. Ohno, O. Pagani, S. Paluch-Shimon, F. Penault-Llorca, A. Prat, H. S. Rugo, G. W. Sledge, D. Spence, C. Thomssen, D. A. Vorobiof, B. Xu, L. Norton and E. P. Winer, "4th ESO-ESMO International Consensus Guidelines for Advanced Breast Cancer (ABC 4)," Ann Oncol, vol. 29, no. 1, pp. 1634-1657, 2018.

5. R. H. Lurie, "2019 Congress Series: Breast Cancer with Updates from 2018 San Antonio Breast Cancer Symposium", in San Antonio Breast Cancer Symposium, Chicago, Illinois, 2019.

6. A. Soran, V. Ozmen, S. Ozbas, H. Karanlik, M. Muslumanoglu, A. Igci, Z. Canturk, Z. Utkan, C. Ozaslan, T. Evrensel, C. Uras, E. Aksaz, A. Soyder, U. Ugurlu, C. Col, N. Cabioglu, B. Bozkurt, A. Uzunkoy, N. Koksal, B. M. Gulluoglu, B. Unal, C. Atalay, E. Yıldırım, E. Erdem, S. Salimoglu, A. Sezer, A. Koyuncu, G. Gurleyik, H. Alagol, N. Ulufi, U. Berberoglu, M. Dulger, O. Cengiz, E. Sezgin and R. Johnson, "Randomized Trial Comparing Resection of Primary Tumor with No Surgery in Stage IV Breast Cancer at Presentation: Protocol MF07-01," Ann Surg Oncol, vol. 25, no. 1, pp. 3141-3149, 2018.

7. W. Xiao, Y. Zou, S. Zheng, X. Hu, P. Liu, X. Xie, P. Yu, H. Tang and X. Xie, "Primary Tumor Resection in Stage IV Breast Cancer: A Systematic Review and Meta-analysis," Eur J of Surg Onc, vol. 44, no. 10, pp. 1504-1512, 2018, doi: 10.1016/j.ejso.2018.08.002.

8. N. A. Vohra, J. Brinkley, S. Kachare and M. Muzaffar, "Primary tumor resection in metastatic breast cancer: A propensity-matched analysis, 1988-2011 SEER data base," Breast J, vol. 24, no. 4, pp. 549-554, 2018, doi.org/10.1111/ tbj.13005.

9. A. Thomas, S. A. Khan, E. A. Chrischilles and M. C. Schroeder, "Initial Surgery and Survival in Stage IV Breast Cancer in the United States, 1988-2011," JAMA Surg, vol. 151, no. 5, pp. 424-431, 2016.

10. W. O. Lane, S. M. Thomas, R. C. Blitzblau, J. K. Plichta, L. H. Rosenberger, O. M Fayanju, T. Hyslop, E. S. Hwang and R. A. Greenup. "Surgical Resection of the Primary Tumor in Women With 
De Novo Stage IV Breast Cancer: Contemporary Practice Patterns and Survival Analysis," Ann Surg, vol. 269, no. 3, pp. 537-544, 2019.

11. S. Lopez-Tarruella, M. J. Escudero, M. Pollan, M. Martín, C. Jara, B. Bermejo, A. Guerrero-Zotano, J. García-Saenz, A. Santaballa, E. Alba, R. Andrés, P. Martínez, L. Calvo, A. Fernández, N. Batista, A. Llombart-Cussac, A. Antón, A. Lahuerta, J. Haba, J. M. López-Veja and E. Carrasco, "Survival impact of primary tumor resection in de novo metastatic breast cancer patients (GEICAM/El Alamo Registry)," Sci Rep, vol. 9, n. 1, 2019.

12. J. A. C Sterne, J. Savović, M. J. Page, R. G. Elbers, N. S. Blencowe, I. Boutron, C. J. Cates, H. Y. Cheng, M. S. Corbett, S. M. Eldridge, M.A. Hernán, S. Hopewel, A. Hróbjartsson, D. R. Junqueira, P. Jüni, J. J. Kirkham, T. Lasserson, T. Li, A. McAleenan, B. C. Reeves, S. Shepperd, I. Shrier, L. A. Stewart, K. Tilling, I. R. White, P. F. Whiting and J. P. T. Higgins. "RoB 2: a revised tool for assessing risk of bias in randomised trials," BMJ, vol. 366, 2019.

13. M. J. Downes, M. L. Brennan, H. C. Williams and R. S. Dean, "Development of a critical appraisal tool to assess the quality of cross-sectional studies (AXIS)," BMJ Open, vol. 6, 2016, doi: 10.1136/bmjopen-2016-011458.

14. R. Badwe, R. Hawaldar, N. Nair, R. Kaushik, V. Parmar, S. Siddique, A. Budrukkar, I. Mittra and S. Gupta, "Locoregional treatment versus no treatment of the primary tumor in metastatic breast cancer: an open-label randomized controlled trial," Lancet Oncol, vol. 16, no. 13, pp. 1380-1388, 2015.

15. S. M. Lim, J. Y. Kim, H. S. Park, S. Park, G. M. Kim, J. Sohn, S. Il Kim, "Effect of primary tumor resection on overall survival in patients with stage IV breast cancer," Breast J, vol. 25, n. 5, pp. 908915, 2019, doi.org/10.1111/tbj.13344. 